Research Article

\title{
Right Coronary Artery Originating from the Left: Do Not Miss the Diagnosis!
}

\author{
Sedat Türkoğlu $(\mathbb{D}$, , Serkan Ünlü $\mathbb{D}$, Gülten Aydoğdu Taçoy, and Murat Özdemir \\ Department of Cardiology, Gazi University School of Medicine, Ankara, Turkey \\ Correspondence should be addressed to Sedat Türkoğlu; sturkol@gmail.com
}

Received 20 November 2017; Accepted 5 February 2018; Published 20 March 2018

Academic Editor: Olivia Manfrini

Copyright ( 92018 Sedat Türkoğlu et al. This is an open access article distributed under the Creative Commons Attribution License, which permits unrestricted use, distribution, and reproduction in any medium, provided the original work is properly cited.

Objective. Left circumflex (LCx) artery originating from the right coronary arterial (RCA) system has been reported as the most common form of anomalous origination of a coronary artery from the opposite sinus (ACAOS). However, some studies claim that RCA originating from the left coronary sinus (LCS) is the most frequent form. The aim of this study was to determine the most common type of ACAOS in a single center. Materials and Methods. The database of the catheterization laboratory was retrospectively searched. All patients who were performed coronary angiography between 1999 and 2006 were included to registry. All examinations were carefully analyzed to determine the most frequent type of ACAOS. Results. We detected ACAOS in 35 cases (16 RCA originating from the LCS, 13 LCx from the RCS or the RCA, and 6 others) out of 5165 coronary angiograms. The most common form was RCA originating from LCS. Moreover, we revealed that 5 cases with RCA originating from the LCS were previously misdiagnosed and not reported as a coronary anomaly. Conclusions. RCA originating from the LCS was the most common form of ACAOS in our registry. The high change of misdiagnosis or underreporting of this anomaly could have biased the true prevalence.

\section{Introduction}

Anomalous origination of a coronary artery from the opposite sinus (ACAOS) represents the most common form of coronary artery anomalies in adults [1-3]. ACAOS locating between the aorta and the pulmonary artery could cause serious consequences, including cardiovascular death [4-7]. The left circumflex (LCx) artery originating from either the proximal right coronary artery (RCA) or the right coronary sinus (RCS) has been reported as the most frequent ACAOS in most studies [1-3, 8-15]. In addition, it is usually accepted as a "benign" anomaly [16] since the course of this anomaly is always retroaortic $[1,14,17,18]$. On the other hand, RCA originating from the left coronary sinus (LCS) usually follows an interarterial course $[1,14,17,18]$; thus, it may be considered as a life-threatening anomaly [16]. The prevalence of coronary anomalies could show regional differences. Moreover, the experience of the operators can highly influence the diagnosis. Therefore, we planned the present study to investigate the prevalence of coronary artery anomalies in patients who were performed coronary angiography in our center.

\section{Materials and Methods}

A consecutive series of 5165 patients undergoing their first coronary angiography during the period between February 1999 and August 2006 were investigated to create our registry. Original coronary angiography reports were first screened with respect to the final diagnosis of ACAOS. After first screening, all angiographic images of 5165 patients were reevaluated with giving particular attention to the presence of the coronary anomalies. All angiograms were evaluated by three independent investigators by using previously published guides $[19,20]$. In case of any difference in opinion, a consensus was reached among readers. Patients with complex congenital heart disease and who were performed recurrent coronary angiographies during the indicated time span were excluded from this analysis. Clinical data concerning participants, such as age, gender, history of hypertension, 
TABLE 1: Prevalence of anomalous origination of a coronary artery from the opposite sinus in 5165 patients who underwent a first coronary angiography.

\begin{tabular}{lcc}
\hline Anomaly & $\begin{array}{c}\text { Number of } \\
\text { patients }\end{array}$ & $\begin{array}{c}\text { Prevalence } \\
(\%)\end{array}$ \\
\hline RCA from LCS & 16 & 0.31 \\
LCx from RCS or proximal RCA & 13 & 0.25 \\
LMCA from RCS & 3 & 0.06 \\
LCx from RCA and LAD from & 1 & 0.02 \\
RCS & 1 & 0.02 \\
LAD from RCS & 1 & 0.02 \\
RCA from LAD
\end{tabular}

LAD: left anterior descending; LMCA: left main coronary artery; LCS: left coronary sinus; LCx: left circumflex; RCA: right coronary artery; RCS: right coronary sinus.

hypercholesterolemia, diabetes mellitus, smoking status, and family history, were carefully noted from records.

\section{Results}

The study included 5165 patients (3465 males and 1700 females; mean age 58.6 years with a range of 17 to 90 years) who underwent a first coronary angiography in our hospital between February 1999 and August 2006 for various indications. A total of 35 patients (24 males and 11 females; mean age 60 years with a range of 21 to 80 years) were found to have ACAOS (prevalence $0.68 \%$ ). The most common anomaly was RCA taking origin from the LCS (16 cases, prevalence $=0.31 \%$ ) (Tables 1 and 2 ). In all those cases, anomalous RCA followed an interarterial course (Figure 1). The second most common anomaly was LCx originating from either the RCS or the proximal RCA (13 cases, prevalence $=0.25 \%)$. In all these cases, the anomalous LCx followed a retroaortic pathway (Figure 2). The next most prevalent anomaly was the left main coronary artery (LMCA) originating from the RCS. There were 3 patients with this condition. The anomalous LMCA followed the septal pathway in two patients, and its course was retroaortic for the other patient.

We determined 3 cases with ACAOS who had a different pathology from mentioned most common three anomalies. In one of these patients, which was published as a case report previously [21], LCx originated from the proximal RCA and followed the retroaortic course, and the left anterior descending (LAD) originated from the RCS by following the pathway on the anterior free wall. In another patient, LAD originated from the RCS and followed the septal course. Lastly, one patient had an anomalous RCA originating from the midregion of LAD. In that case, the anomalous RCA followed the course on the anterior free wall.

\section{Discussion}

ACAOSs represent the most common form of coronary artery anomalies in adults [1-3]. In most of the large conventional angiographic studies in which coronary anomalies were investigated, anomalous origin of the LCx from the RCS or proximal RCA is the most common type of ACAOS
TABLE 2: Baseline patient characteristics.

\begin{tabular}{lccc}
\hline & $\begin{array}{c}\text { All ACAOS } \\
(n=35)\end{array}$ & $\begin{array}{c}\text { RCA from LCS } \\
(n=16)\end{array}$ & $\begin{array}{c}\text { Others* } \\
(n=19)\end{array}$ \\
\hline $\begin{array}{l}\text { Age (years), mean } \pm \\
\text { SD }\end{array}$ & $60 \pm 13.7$ & $55.9 \pm 17.1$ & $63.6 \pm 9.2$ \\
$\begin{array}{l}\text { Male, } n \text { (\%) } \\
\begin{array}{l}\text { Diabetes mellitus, } n \\
(\%)\end{array}\end{array}$ & $24(69)$ & $9(56)$ & $15(79)$ \\
$\begin{array}{l}\text { Current or prior } \\
\text { smoker, } n \text { (\%) }\end{array}$ & $20(57)$ & $2(13)$ & $2(11)$ \\
$\begin{array}{l}\text { Hypertension, } n(\%) \\
\begin{array}{l}\text { Hyperlipidemia, } n \\
(\%)\end{array}\end{array}$ & $19(54)$ & $9(56)$ & $11(58)$ \\
$\begin{array}{l}\text { Family history early } \\
\text { CAD, } n \text { (\%) }\end{array}$ & $3(9)$ & $7(44)$ & $3(16)$ \\
\hline
\end{tabular}

ACAOS: anomalous origination of a coronary artery from the opposite sinus; CAD: coronary artery disease; LAD: left anterior descending; LMCA: left main coronary artery; LCS: left coronary sinus; LCx: left circumflex; RCA: right coronary artery; RCS: right coronary sinus; ${ }^{*}$ others include LCx from RCS or proximal RCA $(n=13)$, LMCA from RCS $(n=3)$, LCx from RCA and LAD from RCS $(n=1)$, LAD from RCS $(n=1)$, and RCA from $\operatorname{LAD}(n=1)$.

having a prevalence of $0.17-0.45 \%$ [1-3, 8-15]. RCA originating from the LCS shows a higher variability of prevalence in these registries. In most of the studies, including the world's largest registry on coronary anomalies [1], it has been reported as the second most common coronary artery anomaly after the anomaly of LCx originating from the proximal RCA or RCS [2, 3, 8-10, 15]. But other studies reveal conflicting results. The anomaly of RCA originating from the LCS was not even reported once in two studies which were performed in Hungary [22] and England [13] by enrolling 7694 and 9153 patients, respectively. On the other hand, two other studies note this anomaly as the most frequent type of ACAOS $[17,18]$. These conflicting findings have usually been attributed to racial and regional differences. In our study, we revealed that in 5 of 16 patients with RCA originating from the LCS anomaly, the diagnosis had been missed in the original coronary angiography report, whereas all other types of ACAOS were diagnosed correctly as an anomaly. If we had only screened our original reporting database, we would have erroneously ended up reporting that the $\mathrm{LCx}$ originating from the RCS or proximal RCA was the most common form of ACAOS, which was not the in fact case. Therefore, we claim that the diagnosis of the cases with RCA originating from the LCS anomaly might have been misdiagnosed/unnoticed in retrospective angiographic series; thus, its currently known prevalence may have been falsely underreported. In this retrospective study, we avoided such an error by reevaluating all coronary angiograms irrespective of the original diagnosis reported at the time of coronary angiography. Moreover, to our knowledge, the only prospectively designed angiographic study found that RCA originating from the LCS is more common than LCx originating from the RCS [23], which is consistent with our findings and results. In addition, all of the recent studies, except one [24], that used computed tomography (CT) angiography, found RCA originating from the LCS as the most common form of ACAOS [25-31]. 


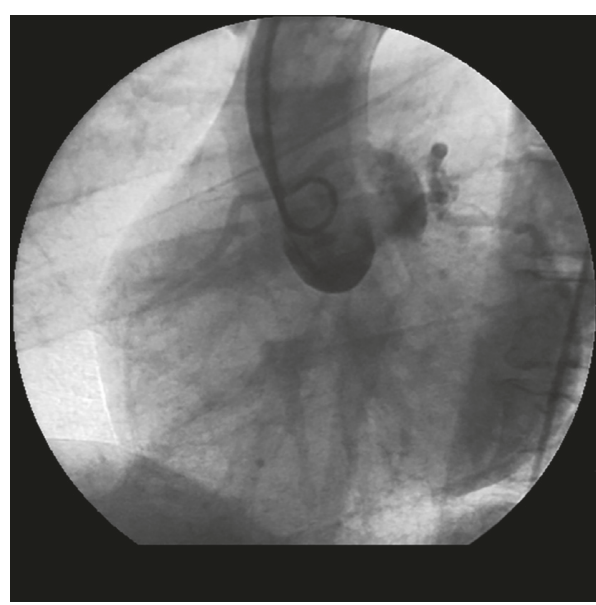

(a)

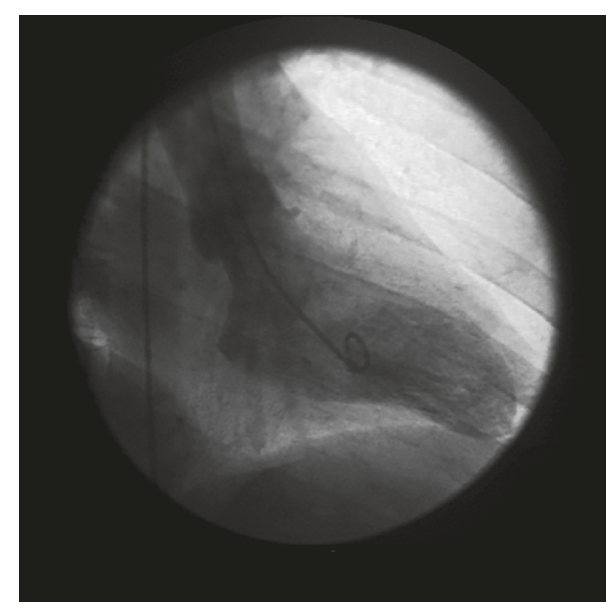

(b)

FIGURE 1: A case which was misdiagnosed as normal coronary arteries. However, with aortography in the left anterior oblique projection (a), it can be recognized that RCA originates from the LCS; with ventriculography in the right anterior oblique projection (b), a mark is seen on the location anterior to aorta, showing interarterial course.

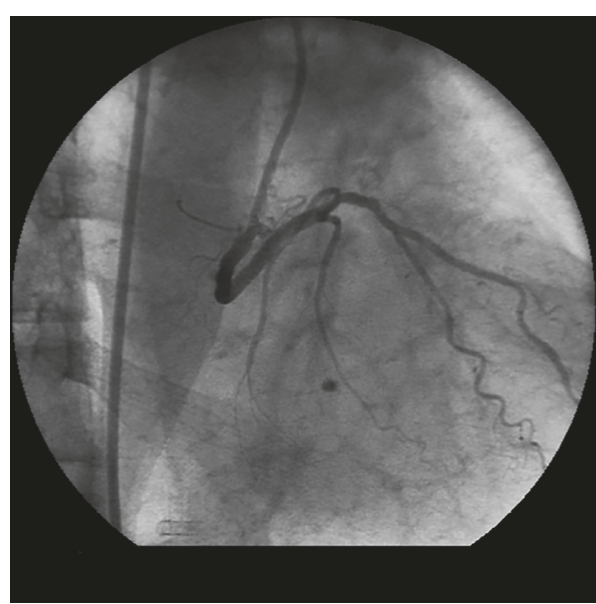

(a)

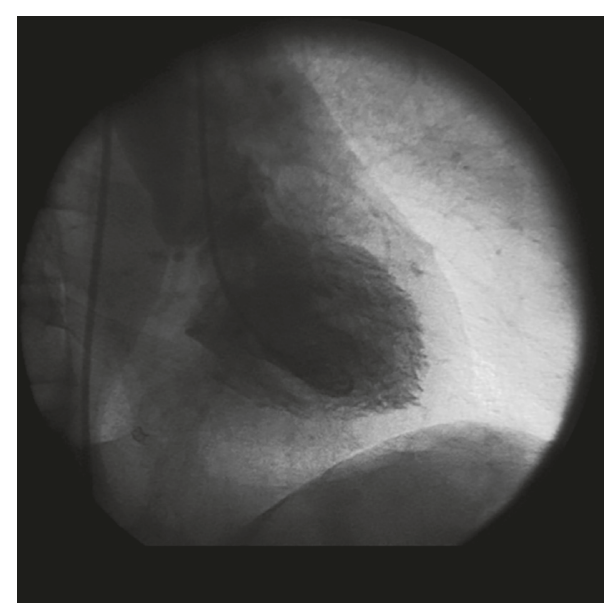

(b)

FIGURE 2: Right coronary sinus injection in the right anterior oblique view: anomalous left circumflex coronary artery is visualized to arise from the right coronary sinus and courses posterior to the aorta (a). Ventriculography in the right anterior oblique view shows a mark posterior to the aorta confirming retroaortic course (b).

This indicates that our findings strongly reflect the real clinical prevalence of coronary anomalies, since CT angiography was shown to be superior to conventional angiography in delineating the origin and the pathway of the anomalous coronary arteries by providing three-dimensional construction of the data [32-34]. So we claim that some cases of RCA originating from the LCS anomaly may have been missed in conventional angiography studies which possibly resulted in lower prevalence of the mentioned anomaly than it should be. On the other hand, diagnosis of anomalous origin of the LCx from the RCS or proximal RCA with conventional angiography is clearly more uncomplicated, leading to a correct diagnosis even performed by a novice clinician.

The anatomy of the coronary arteries that originate from the opposite sinus and follow an interarterial course could result in unwanted consequences and even mortality [4-7].
Although RCA taking origin from the LCS could follow an intraseptal or retroaortic course $[1,30]$, this anomaly usually follows an interarterial path reaching to $88-100 \%$ of the cases $[1,14,17,18,24,27,28,30]$. Therefore, correct diagnosis carries high importance since misdiagnosis most likely results in fatal consequences. Our study suggests that some cases with this anomaly may easily be missed to correctly diagnose at the time of coronary angiography. To avoid such a mistake and its potential fatal complications, in cases where the RCA cannot be cannulated selectively, this anomaly must be kept in mind and every effort should be spent to disclose its presence.

The main deficiency of our study is the lack of clinical follow-up information of patients with coronary anomalies due to retrospective nature of the study. Moreover, no data from additional imaging modalities, including CT angiography, could be used as a result for the same reason. 


\section{Conclusions}

In conclusion, the most common ACAOS was RCA originating from the LCS. Underreporting the prevalence of this anomaly might have biased the true prevalence in the literature.

\section{Conflicts of Interest}

The authors declare that they have no conflicts of interest regarding the publication of this paper.

\section{References}

[1] O. Yamanaka and R. E. Hobbs, "Coronary artery anomalies in 126,595 patients undergoing coronary arteriography," Catheterization and Cardiovascular Diagnosis, vol. 21, no. 1, pp. 28-40, 1990.

[2] M. K. Gol, M. A. Ozatik, A. Kunt et al., "Coronary artery anomalies in adult patients," Medical Science Monitor: International Medical Journal of Experimental and Clinical Research, vol. 8, no. 9, pp. Cr636-Cr641, 2002.

[3] C. Tuncer, T. Batyraliev, R. Yilmaz, M. Gokce, B. Eryonucu, and S. Koroglu, "Origin and distribution anomalies of the left anterior descending artery in 70,850 adult patients: multicenter data collection," Catheterization and Cardiovascular Interventions, vol. 68, no. 4, pp. 574-585, 2006.

[4] R. E. Eckart, S. L. Scoville, C. L. Campbell et al., "Sudden death in young adults: a 25-year review of autopsies in military recruits," Annals of Internal Medicine, vol. 141, no. 11, pp. 829-834, 2004

[5] M. D. Cheitlin, C. M. De Castro, and H. A. McAllister, "Sudden death as a complication of anomalous left coronary origin from the anterior sinus of Valsalva: a not-so-minor congenital anomaly," Circulation, vol. 50, no. 4, pp. 780-787, 1974.

[6] C. Basso, B. J. Maron, D. Corrado, and G. Thiene, "Clinical profile of congenital coronary artery anomalies with origin from the wrong aortic sinus leading to sudden death in young competitive athletes," Journal of the American College of Cardiology, vol. 35, no. 6, pp. 1493-1501, 2000.

[7] A. J. Taylor, J. P. Byers, M. D. Cheitlin, and R. Virmani, "Anomalous right or left coronary artery from the contralateral coronary sinus: "high-risk" abnormalities in the initial coronary artery course and heterogeneous clinical outcomes," American Heart Journal, vol. 133, no. 4, pp. 428-435, 1997.

[8] R. L. Click, D. R. Holmes Jr., R. E. Vlietstra, A. S. Kosinski, and R. A. Kronmal, "Anomalous coronary arteries: location, degree of atherosclerosis and effect on survival-a report from the coronary artery surgery study," Journal of the American College of Cardiology, vol. 13, no. 3, pp. 531-537, 1989.

[9] R. Barriales-Villa, C. Moris, J. C. Sanmartin, E. Fernandez, F. Pajin, and J. M. Ruiz Nodar, "Anomalous coronary arteries originating in the contralateral sinus of Valsalva: registry of thirteen Spanish hospitals (RACES)," Revista Española de Cardiología, vol. 59, no. 6, pp. 620-623, 2006.

[10] C. E. Wilkins, B. Betancourt, V. S. Mathur et al., "Coronary artery anomalies: a review of more than 10,000 patients from the Clayton Cardiovascular Laboratories," Texas Heart Institute Journal, vol. 15, no. 3, pp. 166-173, 1988.

[11] B. R. Chaitman, J. Lesperance, J. Saltiel, and M. G. Bourassa, "Clinical, angiographic, and hemodynamic findings in patients with anomalous origin of the coronary arteries," Circulation, vol. 53, no. 1, pp. 122-131, 1976.
[12] G. Cieslinski, B. Rapprich, and G. Kober, "Coronary anomalies: incidence and importance," Clinical Cardiology, vol. 16, no. 10, pp. 711-715, 1993.

[13] R. M. Donaldson, M. Raphael, R. Radley-Smith, M. H. Yacoub, and D. N. Ross, "Angiographic identification of primary coronary anomalies causing impaired myocardial perfusion," Catheterization and Cardiovascular Diagnosis, vol. 9, no. 3, pp. 237-249, 1983.

[14] R. R. Liberthson, R. E. Dinsmore, S. Bharati et al., "Aberrant coronary artery origin from the aorta: diagnosis and clinical significance," Circulation, vol. 50, no. 4, pp. 774-779, 1974.

[15] D. Kimbiris, A. S. Iskandrian, B. L. Segal, and C. E. Bemis, "Anomalous aortic origin of coronary arteries," Circulation, vol. 58, no. 4, pp. 606-615, 1978.

[16] G. Rigatelli, G. Docali, P. Rossi, A. Bandello, and G. Rigatelli, "Validation of a clinical-significance-based classification of coronary artery anomalies," Angiology, vol. 56, pp. 25-34, no. 1, 2005.

[17] O. Topaz, E. J. DeMarchena, E. Perin, L. S. Sommer, S. M. Mallon, and R. A. Chahine, "Anomalous coronary arteries: angiographic findings in 80 patients," International Journal of Cardiology, vol. 34, no. 2, pp. 129-138, 1992.

[18] N. Garg, S. Tewari, A. Kapoor, D. K. Gupta, and N. Sinha, "Primary congenital anomalies of the coronary arteries: a coronary: arteriographic study," International Journal of Cardiology, vol. 74, no. 1, pp. 39-46, 2000.

[19] T. Ishikawa and P. W. Brandt, "Anomalous origin of the left main coronary artery from the right anterior aortic sinus: angiographic definition of anomalous course," American Journal of Cardiology, vol. 55, no. 6, pp. 770-776, 1985.

[20] H. Serota, C. W. Barth III, C. A. Seuc, M. Vandormael, F. Aguirre, and M. J. Kern, "Rapid identification of the course of anomalous coronary arteries in adults: the "dot and eye" method," American Journal of Cardiology, vol. 65, no. 13, pp. 891-898, 1990.

[21] S. Turkoglu and M. Ozdemir, "Anomalous origin of the left circumflex coronary artery from the right coronary artery and the left anterior descending artery from the right coronary sinus," Journal of Invasive Cardiology, vol. 18, pp. E214-E216, 2006.

[22] A. Kardos, L. Babai, L. Rudas et al., "Epidemiology of congenital coronary artery anomalies: a coronary arteriography study on a central European population," Catheterization and Cardiovascular Diagnosis, vol. 42, no. 3, pp. 270-275, 1997.

[23] P. Angelini, "Coronary artery anomalies: an entity in search of an identity," Circulation, vol. 115, no. 10, pp. 1296-1305, 2007.

[24] M. P. Opolski, J. Pregowski, M. Kruk et al., "Prevalence and characteristics of coronary anomalies originating from the opposite sinus of Valsalva in 8,522 patients referred for coronary computed tomography angiography," American Journal of Cardiology, vol. 111, no. 9, pp. 1361-1367, 2013.

[25] S. Fujimoto, T. Kondo, T. Orihara et al., "Prevalence of anomalous origin of coronary artery detected by multidetector computed tomography at one center," Journal of Cardiology, vol. 57, no. 1, pp. 69-76, 2011.

[26] C. Graidis, D. Dimitriadis, V. Karasavvidis et al., "Prevalence and characteristics of coronary artery anomalies in an adult population undergoing multidetector-row computed tomography for the evaluation of coronary artery disease," BMC Cardiovascular Disorders, vol. 15, no. 1, p. 112, 2015.

[27] H. J. Lee, Y. J. Hong, H. Y. Kim et al., "Anomalous origin of the right coronary artery from the left coronary sinus with an interarterial course: subtypes and clinical importance," $R a$ diology, vol. 262, no. 1, pp. 101-108, 2012. 
[28] L. J. Zhang, G. F. Yang, W. Huang, C. S. Zhou, P. Chen, and G. M. Lu, "Incidence of anomalous origin of coronary artery in 1879 Chinese adults on dual-source CT angiography," Netherlands Heart Journal, vol. 18, no. 10, pp. 466-470, 2010.

[29] C. Pan, G. Azhati, Y. Xing, Y. Wang, and W. Liu, "Comparison of congenital coronary artery anomalies between Uyghur and Han: a multi-slice computed tomography study in Xinjiang, China," Chinese Medical Journal, vol. 128, no. 1, pp. 15-19, 2015.

[30] M. K. Cheezum, B. Ghoshhajra, M. S. Bittencourt et al., "Anomalous origin of the coronary artery arising from the opposite sinus: prevalence and outcomes in patients undergoing coronary CTA," European Heart JournalCardiovascular Imaging, vol. 18, no. 2, pp. 224-235, 2017.

[31] J. Amado, M. Carvalho, W. Ferreira, P. Gago, V. Gama, and N. Bettencourt, "Coronary arteries anomalous aortic origin on a computed tomography angiography population: prevalence, characteristics and clinical impact," International Journal of Cardiovascular Imaging, vol. 32, no. 6, pp. 983-990, 2016.

[32] P. M. van Ooijen, J. Dorgelo, F. Zijlstra, and M. Oudkerk, "Detection, visualization and evaluation of anomalous coronary anatomy on 16-slice multidetector-row CT," European Radiology, vol. 14, no. 12, pp. 2163-2171, 2004.

[33] H. Shi, A. J. Aschoff, H. J. Brambs, and M. H. Hoffmann, "Multislice CT imaging of anomalous coronary arteries," European Radiology, vol. 14, no. 12, pp. 2172-2181, 2004.

[34] E. Memisoglu, G. Hobikoglu, M. S. Tepe, T. Norgaz, and T. Bilsel, "Congenital coronary anomalies in adults: comparison of anatomic course visualization by catheter angiography and electron beam CT," Catheterization and Cardiovascular Interventions, vol. 66, no. 1, pp. 34-42, 2005. 


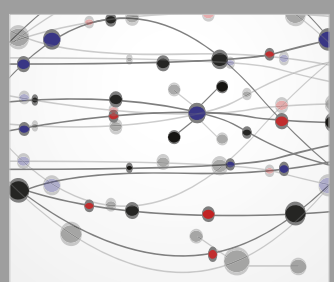

The Scientific World Journal
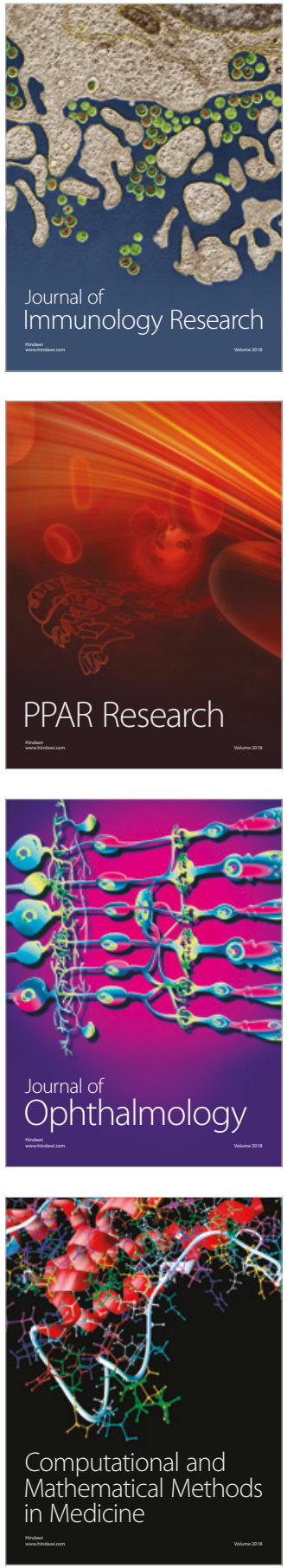

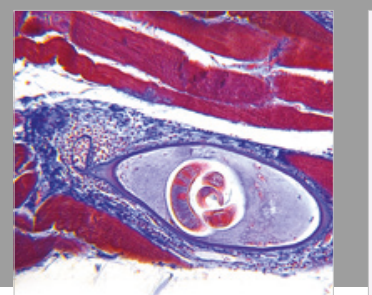

Gastroenterology Research and Practice

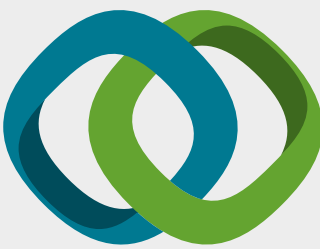

\section{Hindawi}

Submit your manuscripts at

www.hindawi.com
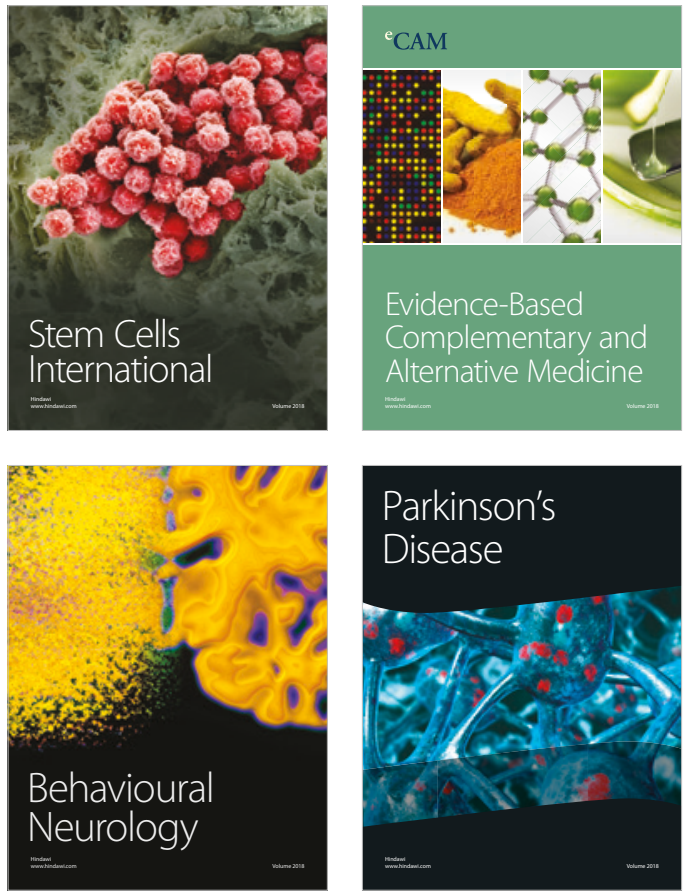

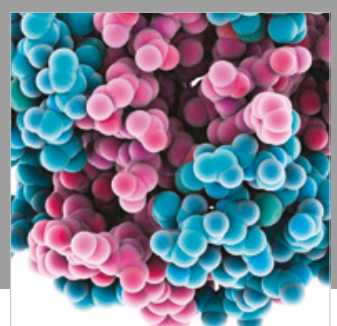

ournal of

Diabetes Research

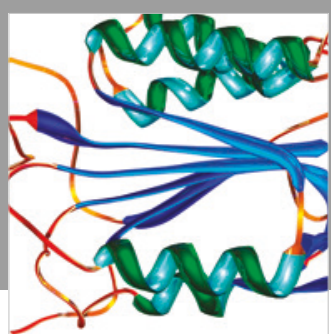

Disease Markers
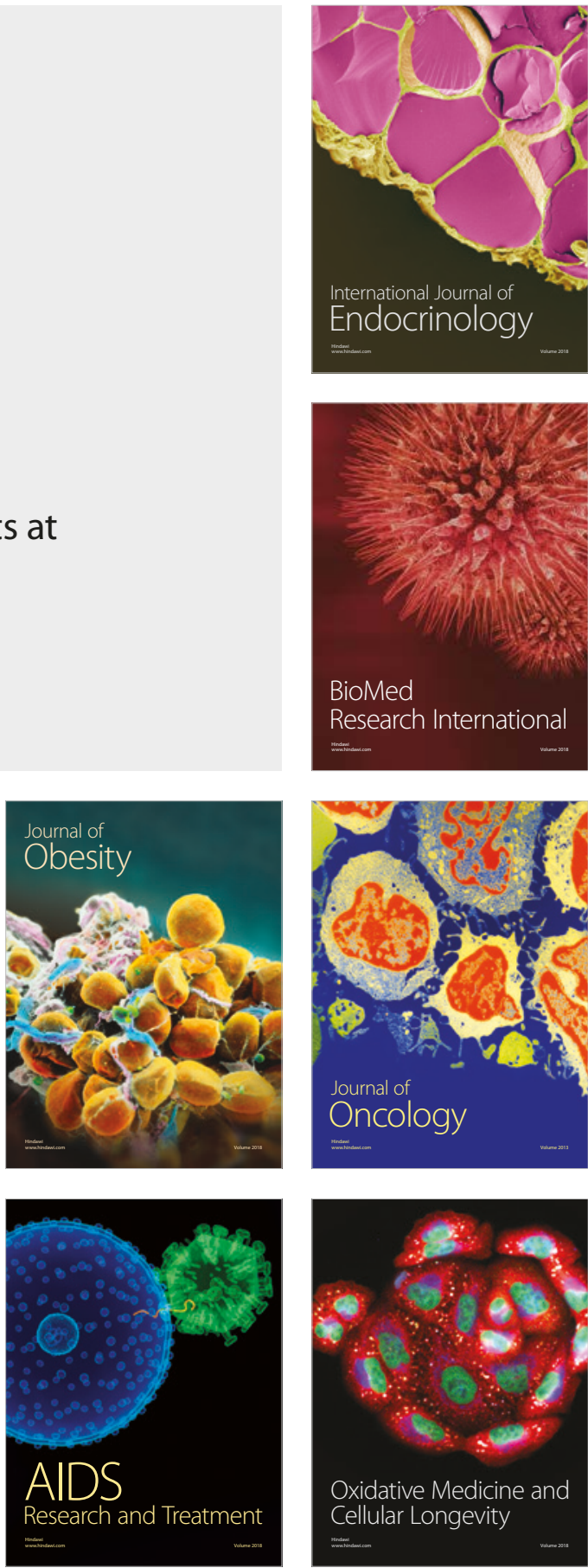